\title{
An evidence-based review of hip-focused neuromuscular exercise interventions to address dynamic lower extremity valgus
}

This article was published in the following Dove Press journal:

Open Access Journal of Sports Medicine

25 August 2015

Number of times this article has been viewed

\author{
Kevin R Ford' \\ Anh-Dung Nguyen ${ }^{2}$ \\ Steven L Dischiavi' \\ Eric J Hegedus' \\ Emma F Zuk ${ }^{2}$ \\ Jeffrey B Taylor' \\ 'Department of Physical Therapy, \\ High Point University, High Point, NC, \\ USA; ${ }^{2}$ Department of Athletic Training, \\ School of Health Sciences, High Point \\ University, High Point, NC, USA
}

\begin{abstract}
Deficits in proximal hip strength or neuromuscular control may lead to dynamic lower extremity valgus. Measures of dynamic lower extremity valgus have been previously shown to relate to increased risk of several knee pathologies, specifically anterior cruciate ligament ruptures and patellofemoral pain. Therefore, hip-focused interventions have gained considerable attention and been successful in addressing these knee pathologies. The purpose of the review was to identify and discuss hip-focused exercise interventions that aim to address dynamic lower extremity valgus. Previous electromyography, kinematics, and kinetics research support the use of targeted hip exercises with non-weight-bearing, controlled weight-bearing, functional exercise, and, to a lesser extent, dynamic exercises in reducing dynamic lower extremity valgus. Further studies should be developed to identify and understand the mechanistic relationship between optimized biomechanics during sports and hip-focused neuromuscular exercise interventions.
\end{abstract}

Keywords: dynamic lower extremity valgus, hip neuromuscular control, ACL injury rehabilitation, patellofemoral pain, hip muscular activation

\section{Introduction}

Hip-focused neuromuscular exercise interventions have gained considerable attention for addressing a myriad of lower extremity injuries. Most notably, anterior cruciate ligament (ACL) ruptures and patellofemoral pain (PFP) are two knee pathologies that may benefit from improved proximal strength and neuromuscular control strategies. ${ }^{1}$ Deficits in proximal hip strength or neuromuscular control may lead to dynamic lower extremity valgus. ${ }^{2}$ Dynamic lower extremity valgus is operationally defined as a combination of motions and rotations in the lower extremity, including hip adduction and internal rotation, knee abduction, tibial external rotation and anterior translation, and ankle eversion. ${ }^{3}$ During sport movements, dynamic lower extremity valgus often presents as a knocked-knee posture during deceleration during double leg and single leg tasks (Figure 1). Importantly, knee abduction moment, which directly contributes to dynamic lower extremity valgus, was a significant predictor for future ACL injury risk with $73 \%$ sensitivity and $78 \%$ specificity in a prospective study of young female athletes. ${ }^{2}$ Frontal plane knee motion was predictive, along with hip internal/external rotation moment, of second ACL injury risk in young athletes who returned to their previous sport following reconstructive surgery and rehabilitation. ${ }^{4}$ Additionally, a recent investigation identified that high knee abduction moment was predictive of both PFP and ACL injury risk in young female athletes. ${ }^{5}$
Correspondence: Kevin R Ford Department of Physical Therapy, High Point University, 833 Montlieu Avenue, High Point, NC 27268, USA

$\mathrm{Tel}+\mathrm{I} 33684 \mid 9495$

Fax + I 3368885020

Email kford@highpoint.edu 


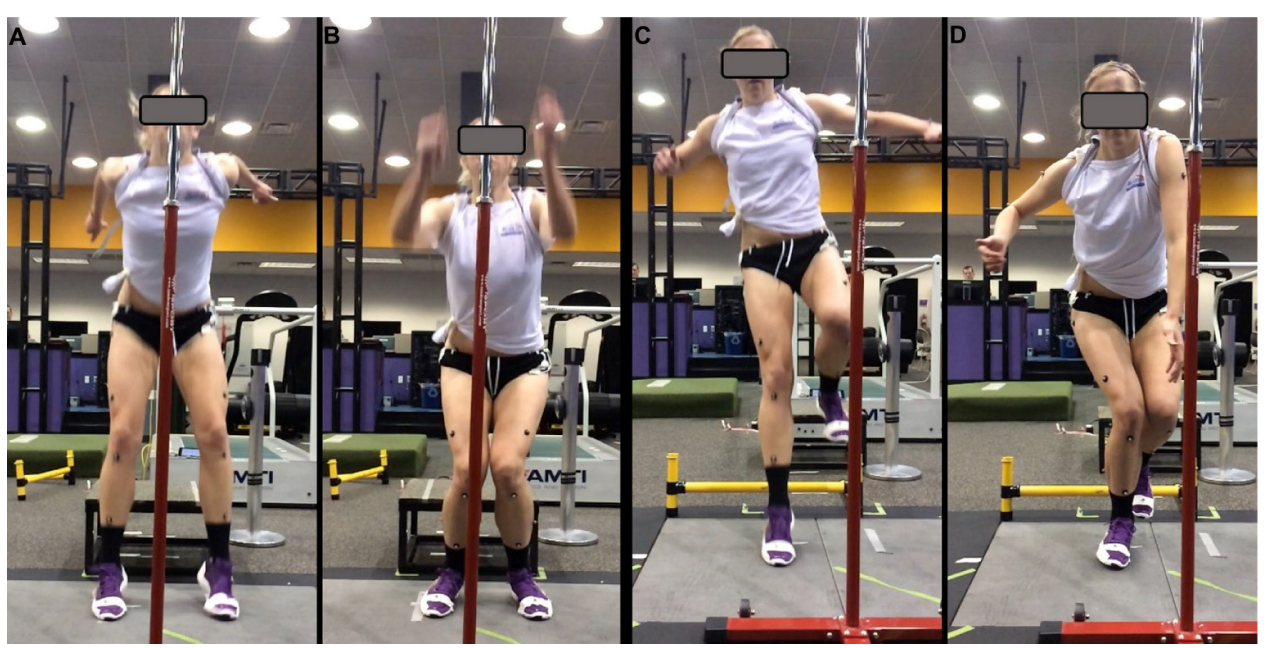

Figure I Dynamic lower extremity valgus.

Notes: (A) Athlete lands during a double leg drop vertical jump at initial contact and (B) immediately displays dynamic lower extremity valgus on both legs. (C) Athlete lands during a single leg hop and (D) exhibits dynamic lower extremity valgus on the right leg.

Sex differences in the incidence of both PFP and non-contact ACL injury have led to a plethora of comparisons between males and females, indicating that the higher incidence of these two pathologies in females may be due to faulty lower extremity biomechanics and hip weakness. Biomechanically, it has been widely reported that females exhibit increased lower extremity valgus alignment and load compared with males during landing and pivoting movements, ${ }^{6-18}$ which was confirmed in a recent systematic review that consistently identified that females land with increased knee abduction across a variety of landing conditions. ${ }^{19}$ Similar lower extremity valgus alignments are often demonstrated by females at the time of ACL injury. ${ }^{20-22}$

Additionally, males have longitudinal increases in hip strength during adolescent growth compared with no strength changes in females. ${ }^{23}$ The result of these sex differences following growth and development is that males have greater overall hip strength compared with females. ${ }^{23}$ This strength difference aligns with the divergent sex-specific patterns of $\mathrm{ACL}$ and patellofemoral joint injury rates. Competitive, collegiate male cross-country runners exhibit significantly greater hip extension and abduction strength measured isokinetically compared with female runners. ${ }^{24}$ Additionally, runners with lower hip abductor and hip extensor strength exhibit greater frontal plane and transverse plane hip motion. ${ }^{25} \mathrm{~A}$ systematic review that investigated hip strength in patients with PFP found strong evidence that hip abduction, external rotation, and extension strength were decreased compared with uninjured control subjects. ${ }^{26}$ Conflicting data exist on the specific movement patterns that may be present in patients with active PFP; however, the inability to eccentrically control hip adduction and internal rotation may lead to greater dynamic lower extremity valgus commonly seen during landing, squatting, and running. ${ }^{27,28}$

Altered neuromuscular control strategies during landing may be a potential factor related to lower extremity and ACL injuries in women athletes..$^{29,30}$ In a study of 315 young athletes, males had greater hip flexion at initial contact and greater hip extensor moment compared with females. ${ }^{31}$ There was also significant preference to underutilize the hip compared with the knee extensors in females, which indicates a sex-specific hip strategy during drop vertical jumps. Decker et $\mathrm{al}^{32}$ showed a decrease in negative joint work (decreased eccentric muscle contraction to absorb landing forces) at the hip in females compared with males during landing. Similarly, ACL reconstructed patients had greater hip moments during the stance phase of gait that may provide increased protection for the ACL. ${ }^{33}$ Patients with patellar tendinopathy also displayed increased hip joint moments during hopping compared with controls. ${ }^{34}$ Proximal mechanisms may play a significant role in neuromuscular control strategies for controlling and compensating for knee loading during a myriad of complex movements. Neuromuscular training positively alters hip kinematics and kinetics. ${ }^{35}$ Lephart et $\mathrm{al}^{35}$ found increased hip flexion at initial contact and increased peak internal hip extensor moment following a plyometric training protocol. These authors suggested that the modifications at the hip likely increase the hamstring forces that protect the ACL. ${ }^{35}$ Hip posture may play an important role in the mechanical efficiency of hamstrings in relation to quadriceps. ${ }^{36}$

Clearly, the hip plays a central role in dynamic lower extremity valgus. The purpose of the clinically related narrative, 
aimed at sports medicine clinicians, was to identify and discuss hip-focused exercise interventions that aim to address dynamic lower extremity valgus. Specifically, hip muscle activation, strength, and biomechanical outcomes are presented. Furthermore, we discuss practical applications that may be utilized both clinically and in future randomized controlled trials.

\section{Functional anatomy}

Since strength, activation, and control of the hip play a critical role in dynamic valgus, understanding the functional anatomy of the hip is foundational in developing any successful intervention program. The gluteus medius is the primary abductor of the hip ${ }^{37-39}$ and receives assistance in abduction from the gluteus minimus and the piriformis. The proximal attachment of gluteus medius is along the outer edge of the iliac crest and is fan-shaped, spanning the iliac crest from the anterior superior iliac spine to the posterior superior iliac spine. The muscle tapers into a strong tendon and attaches distally on the posterosuperior portion of the greater trochanter. ${ }^{40}$ The gluteus medius is specifically defined by three parts, anterior, middle, and posterior, that are approximately equal in volume. The anterior and middle fibers run almost vertical while the posterior fibers run horizontal and almost parallel to the neck of the femur. ${ }^{41}$ Using fine wire electromyography (EMG), the three segments of the gluteus medius have been found to function in a phasic pattern during submaximal functional activities such as walking, but were found to activate (both onset and duration) more simultaneously during maximal levels of activity such as the support phases of descending stairs. ${ }^{42,43}$

The gluteus maximus is the largest muscle in the gluteal region and one of the largest muscles in the body. ${ }^{37}$ The proximal attachments of the gluteus maximus are along the posterior gluteal line of the ilium, dorsal surface of the sacrum and coccyx, and the sacrotuberous ligament. It slopes inferolaterally at a $45^{\circ}$ angle across the ischial tuberosity and attaches distally into the superficial fibers of the iliotibial tract and the gluteal tuberosity of the femur. ${ }^{37,44}$ While the gluteus medius is the primary abductor of the hip, the gluteus maximus functions primarily as an extensor but also as an external rotator of the hip, allowing the gluteus maximus to control motions in the sagittal and transverse planes. ${ }^{37}$

Proper functioning of the posterolateral hip musculature during single limb weight bearing is essential to providing proximal stability for lower extremity motion. Specifically, the roles of these muscles are to stabilize the pelvis in the frontal and transverse planes to maintain a level pelvis and control rotation at the hip..$^{37-39,41,43,45,46}$ In the frontal plane, the hip abductors must produce a large abduction torque to counteract the adduction torque produced from the product of body weight and its larger external moment arm acting at the hip. ${ }^{47}$ Failure to produce the abduction force is observed as a Trendelenburg posture, with the contralateral pelvis dropping. ${ }^{47}$ The important role of the hip abductors in stabilizing the pelvis during single limb function is further illustrated during the midstance phase of gait where activation and force production of the abductors have been observed to be the greatest. ${ }^{48,49}$ In the transverse plane, the abductors and external rotators work together to control hip and pelvis motion. ${ }^{45,46}$ Hence, weakness or inefficiency of the posterolateral hip musculature would decrease stability of the hip when loaded in a single limb weight-bearing stance, resulting in an inability to maintain a neutral alignment of the hip and knee. Therefore, much attention has been directed at correcting or improving hip strength or activation and its role in controlling dynamic lower extremity valgus.

\section{Muscular activation with hip-focused exercises}

Hip muscle activation, particularly of the gluteus medius and gluteus maximus, have been examined across a variety of exercises commonly used during interventions. EMG is commonly used to quantify the motor-unit activity in a muscle or muscle group during intervention exercises and is reported as the percentage of a maximal voluntary isometric contraction (\% MVIC). A greater level of muscle activity has been assumed to lead to muscle strengthening effects. It has been suggested that muscle activation during an exercise should reach a minimum of $40 \%-60 \%$ MVIC in order to achieve strength gains. ${ }^{50}$ This has led to a myriad of studies that have compared muscle activity during exercises. This section summarizes the observed gluteus maximus and gluteus medius muscle activation during non-weight-bearing, controlled weight-bearing, and functional exercises. The effects of common modifications to these exercises on hip muscle activation are also discussed.

\section{Non-weight-bearing exercises}

Non-weight-bearing hip exercises are often initiated to target a specific muscle group in isolation, or during the beginning stages of rehabilitation. Common exercises that have been suggested to target the gluteus medius include side-lying hip abduction, clam-shell exercises, and bridging exercises. Side-lying hip abduction (Figure 2A) is one of the most consistently reported exercises in the literature. 


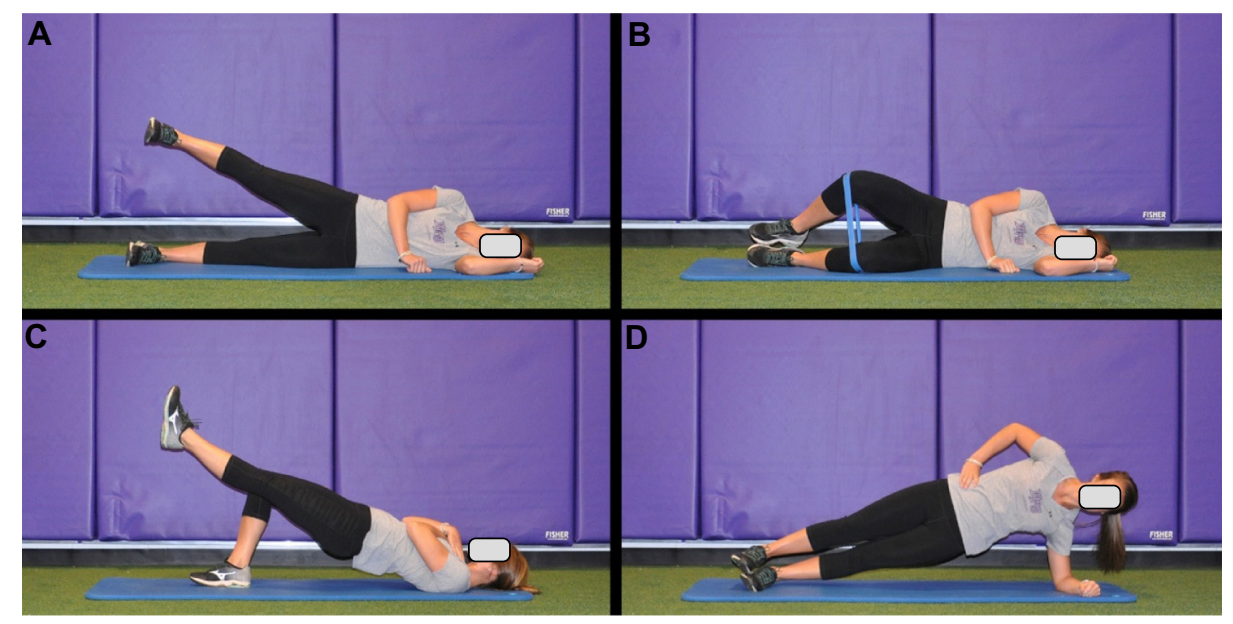

Figure 2 Common non-weight-bearing exercises.

Notes: (A) Side-lying hip abduction. (B) Side-lying clam with resistance. (C) Unilateral supine bridge. (D) Side-bridge (plank).

Activation of the gluteus medius during this exercise have been reported to range from $23 \%$ to $81 \%$ MVIC. ${ }^{51-55}$ The side-lying hip abduction exercise was observed to have $16 \%-43 \%$ greater gluteus medius activation in studies ${ }^{51,53}$ when compared with the clam-shell exercise, where the hip is abducted while keeping the feet together, with the hip and knees flexed (Figure 2B). This is supported biomechanically as the external hip adduction moment would be greater with the hip and knee extended compared with a flexed position. When comparing gluteus medius activation between sidelying hip abduction exercise and a unilateral supine bridge exercise (Figure 2C), the reports are somewhat conflicting. Two studies ${ }^{53,54}$ observed $8 \%-13 \%$ less gluteus medius activation during the unilateral supine bridge exercise, whereas one study ${ }^{55}$ observed an $8 \%$ greater gluteus medius activation during the side-lying hip abduction. The reasons for these conflicting findings are unknown.

While the side-lying hip abduction exercise appears to effectively activate the gluteus medius, the side-bridge (plank) exercise has been shown to require greater activation of this muscle. The side-bridge exercise (Figure 2D) is performed in a side-lying position with the trunk supported by the upper extremity. The exercise is performed by lifting the hip off the ground while maintain a neutral alignment of the trunk, hips, and knees. The side-bridge has been observed to require $35 \%-40 \%$ greater activation than the side-lying hip abduction exercise. ${ }^{53,55}$ The greater activation during the side-bridge is likely due to the increased demand of the gluteus medius to abduct the hip by lifting the body's mass and the need to stabilize the pelvis in the sagittal plane.

Common non-weight-bearing exercises to target the gluteus maximus are supine bridging exercises where hip extension is performed by lifting the body's mass. Gluteus maximus activation have been observed to range between $17 \%$ and $25 \%$ MVIC during a bilateral supine exercise and between $35 \%$ and $54 \%$ MVIC during a unilateral supine bridging exercise. ${ }^{53-55}$ The magnitudes of gluteus maximus activation during these bridging exercises are similar compared with the simplest non-weight-bearing exercise with individuals extending the hip against gravity. This is commonly done in a quadruped position and extending the hip while the knee is flexed. Direct comparison between the quadruped hip extension and unilateral bridging exercises reveals an approximately 5\% difference in gluteus maximus activation. ${ }^{53,54}$ However, the observed gluteus maximus activation during these exercises may be misleading and not result in strength gains, because there is evidence to suggest that simply contracting the gluteal muscles in a standing position activates the gluteus maximus $20 \%$ more than performing a unilateral bridging exercise.

\section{Controlled weight-bearing exercises}

As previously mentioned, the hip abductors must produce a large abduction torque to counteract the adduction torque produced from the product of the body weight and its larger external moment arm acting at the hip to stabilize the pelvis during single limb activities. ${ }^{48,49}$ Controlled weight-bearing exercises commonly used to target the gluteus medius include hip hikes (pelvic drops), single limb squats (Figure 3A), and lateral step-ups (Figure 3B). Activation of the gluteus medius during these exercises has been reported to range between $38 \%$ and $58 \%$ MVIC for hip hikes, $38 \%$ and $60 \%$ MVIC for lateral step-ups, and $48 \%$ and $82 \%$ MVIC for single limb squats. ${ }^{51-57}$ Only one study was found that examined 

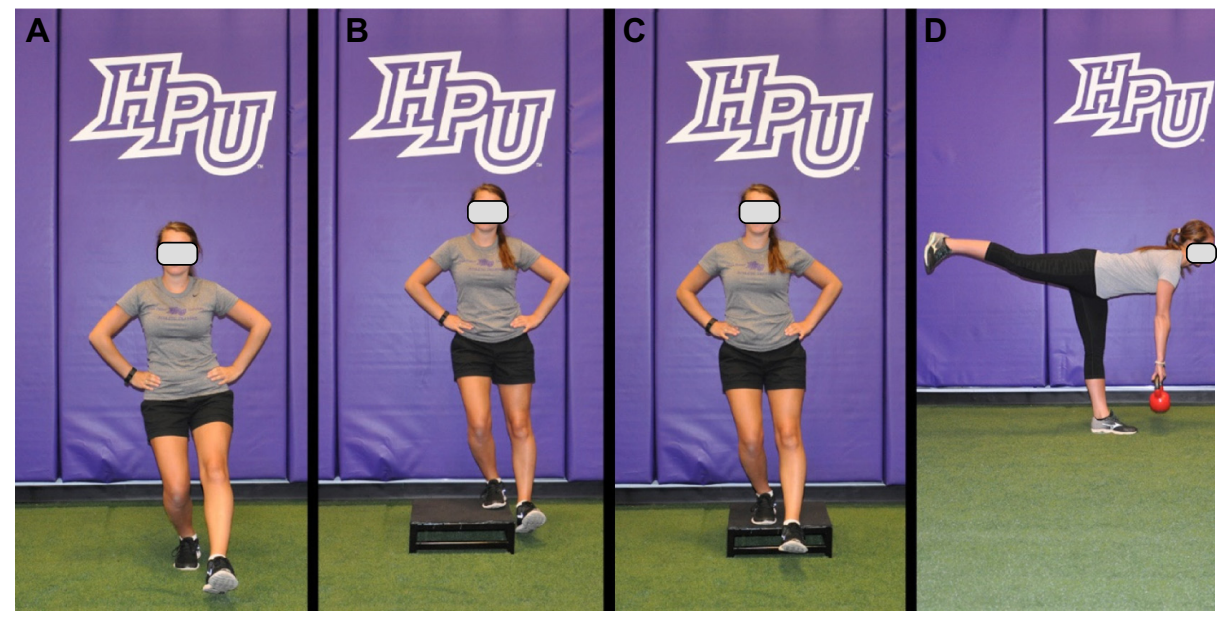

Figure 3 Common controlled weight-bearing exercises.

Notes: (A) Single leg squat. (B) Lateral box step-ups. (C) Forward box step-down.

(D) Single leg dead lift.

differences across all three exercises, and it reported a $22 \%$ and $24 \%$ greater activation of the gluteus medius during a single limb squat exercise compared with a lateral step-up and hip hike exercise, respectively. ${ }^{53}$ Collectively, these findings suggest that there is a negligible difference between the hip hike and lateral step-up exercises. However, it appears that there is a meaningful increase in the demand of the gluteus medius during a single limb squat.

Single limb squat, step-up (lateral and forward, Figure 3C), and single limb dead lift (Figure 3D) exercises are controlled weight-bearing exercises that are commonly used to target the gluteus maximus. Activation of the gluteus maximus during these exercises has been reported to range between $41 \%$ and $71 \%$ MVIC for single limb squats, $29 \%$ and $64 \%$ MVIC for lateral step-ups, $23 \%$ and $74 \%$ MVIC for forward step-ups, and 59\% MVIC for single limb dead lifts. ${ }^{51,53-57}$ Differences in gluteus maximus activation between the forward and lateral step-up exercises are conflicting, with one study ${ }^{56}$ reporting an $18 \%$ increase and another study ${ }^{53}$ reporting a $9 \%$ decrease in gluteus maximus activation during the forward versus the lateral step-up exercise. There is also conflicting evidence when comparing single limb squat and the single limb dead lift exercises, with one study ${ }^{51}$ reporting no difference and another study ${ }^{53}$ reporting a $12 \%$ greater gluteus maximus activation during the squat exercise. There is consistent evidence suggesting that there is a $7 \%-16 \%$ increase in gluteus maximus during the single limb squat compared with the forward step-up exercise. ${ }^{53,57}$ Only one study ${ }^{53}$ was found that examined gluteus maximus activation across all four exercises, and it reported a high level of activation during all controlled weight-bearing exercises, with the greatest activation observed during the single limb squat.

\section{Functional exercises}

Increasing the complexity of exercises that continue to target the gluteal muscles in a more dynamic and functional movement pattern is a necessary component for an intervention program. Functional exercises commonly used to target the gluteus medius and gluteus maximus include lateral band walks (Figure 4A), side lunges (Figure 4B), forward lunges (Figure 4C), and rear lunges (Figure 4D). There are limited studies that have examined activation of the gluteal muscles during these exercises. Gluteus medius activation during these exercises have been reported to be $30 \%-61 \%$ MVIC for lateral band walks, 39\% MVIC for side lunges, and $19 \%-42 \%$ MVIC for forward lunges. Gluteus maximus activation during these exercises have been reported to be 27\%-28\% MVIC for lateral band walks, 41\% MVIC for side lunges, and $20 \%-44 \%$ MVIC for forward lunges. ${ }^{51,54,55}$ Only one study ${ }^{51}$ was found that compared the gluteal muscle activation across all three exercises. A comparison of gluteus medius activation between the functional exercises reported a $22 \%-25 \%$ greater activation of the gluteus medius during the lateral band walk compared with the lunge exercises while there was negligible difference between the lunge exercises. A comparison of gluteus maximus activation showed a negligible difference between the forward and side lunge exercises, but there was $14 \%-17 \%$ greater gluteus maximus activation compared with the lateral band walks. These findings are not unexpected, as the lunge exercises require greater hip dynamic flexion that would increase the demand on the gluteus maximus.

Plyometric (ballistic) exercises are often used in injury prevention settings or during the latter stages of rehabilitation. Plyometric exercise has been previously operationally 


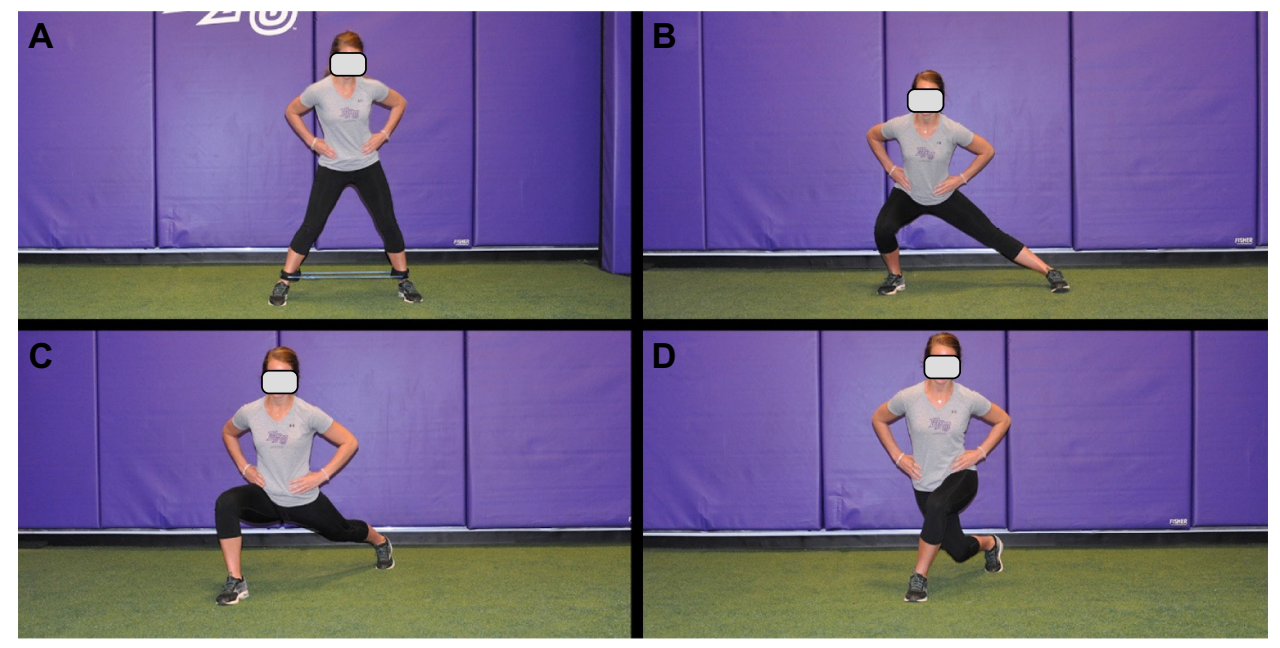

Figure 4 Common functional exercises.

Notes: (A) Lateral resisted band walks. (B) Side lunges. (C) Forward lunges. (D) Rear cross-over lunges. Note that during the rear cross-over lunge it is extremely challenging to control the pelvis, which results in apparent lower extremity valgus. Care should be taken to progress the exercises and limit step distances as appropriate.

defined as an "... activity that involves and capitalizes on the mechanisms of the stretch-shortening cycle to increase the efficiency of force production at a joint or increase performance". ${ }^{58}$ A number of papers provide detailed exercise descriptions and progressions. ${ }^{58-61}$ These exercises are important to assess readiness for return to play, but may also provide therapeutic benefit by preferentially recruiting the gluteus medius and maximus musculature. Gluteus medius muscle activity is highest during single-limb sagittal plane hurdle hops (100\% MVIC), double-limb sagittal plane hurdle hops (61\% MVIC), and split squat jumps (62\% MVIC), with lesser activation during non-sagittal plane double-limb landings in the frontal (40\% MVIC) and transverse (47\% MVIC) planes. ${ }^{62}$ Similarly, the gluteus maximus is most highly activated during double-limb (63\% MVIC) and single-limb (69.4\% MVIC) sagittal plane landings, and less active in other planes ( $<40 \%$ MVIC). ${ }^{62}$ Of note, these results are during a land, and do not incorporate a subsequent jump which is common during plyometric activities. True plyometric activities, including a rapid change of direction, elicit significantly higher muscle activation (150\%-190\% MVIC) than isolated landings or controlled exercises. ${ }^{63}$ Continued work is needed to explore gluteal activation patterns during other commonly used functional exercises.

\section{Influence of exercise modification on gluteal activation}

During non-weight-bearing exercises, limb position, and joint angle can directly influence the activation of the gluteal muscles. Specifically, there is evidence to suggest that rotation at the hip during the side-lying hip abduction exercise can directly influence the magnitude of gluteus medius activation. ${ }^{64}$ It was reported that activation of the gluteus medius during the side-lying hip abduction exercise was $16 \%$ greater with the hip internally rotated than with the hip in neutral. In addition, gluteus maximus activation can be directly influenced by the position of the hip in the sagittal plane during non-weight-bearing hip extension exercises. ${ }^{65}$ There is evidence to suggest that activation of the gluteus maximus is $12 \%-14 \%$ greater at $30-60$ degrees of hip flexion compared with 90 degrees of hip flexion. Collectively, these data suggest that activation of the gluteal muscles is dependent on the length-tension curve where the gluteal muscles may have the greatest activation when they are close to their ideal length. These conclusions are based on hip muscle activation during isometric contractions. Additional work is needed to examine these relationships during isotonic exercises typically used in intervention programs.

The position of the trunk during controlled weightbearing and functional exercises has been suggested to influence the demands on the hip muscles. Powers ${ }^{66}$ discusses this relationship where trunk position, either in the sagittal or frontal plane, that moves the body center of mass (and resultant ground reaction force vector) away from the hip joint will increase the demand placed on the hip muscles. This theory has been supported by empirical evidence that reports greater hip muscle activation during jumping and running tasks with the trunk in a more flexed position. ${ }^{67,68}$ There are limited studies that have examined the role of the trunk during weight-bearing and/or functional exercises commonly used in intervention programs. Only one study could be found that examined the influence of sagittal plane trunk 
position on gluteus maximus activation during a forward lunge. ${ }^{69}$ The authors reported that there was a $6 \%$ increase in gluteus maximus activation during a forward lunge with the trunk forward compared with the trunk in an erect position. Further research is needed to clarify the effects of modifications of exercises on hip muscle activation.

\section{Precautions in interpreting gluteal muscle activation research}

As previously mentioned, it has been suggested that muscle activation during an exercise should reach a minimum of $40 \%-60 \%$ MVIC in order to achieve strength gains. ${ }^{50}$ These values were derived through procedures that normalized the EMG signals during exercise to the peak root mean square amplitude during MVICs at specific joint angles. The Journal of Electromyography and Kinesiology standards for reporting EMG data advised authors to report such information as the joint angle and/or muscle length during the MVIC, and the rate of rise of force. This implies that these factors will influence the EMG signal during MVICs and, consequently, the normalized values observed during exercises.

The values summarized in the preceding sections were reported as normalized values using various methods when assessing MVICs. Therefore, it should not be concluded that exercises reported to exceed $40 \%-60 \%$ MVIC will achieve strength gains. Clinicians should examine the comparisons between exercises, within studies, to determine exercises that have been shown to induce greater muscle activation when initiating exercises during clinical practice.

\section{Biomechanical and strength outcomes with hip-focused interventions}

A number of recent studies have examined the effects of hipfocused intervention programs on multi-planar hip strength and lower extremity biomechanical measures of dynamic lower extremity valgus (Table 1 ). ${ }^{70-80}$ These programs have been wide-ranging in their implementation, based largely on

Table I Components, strength, and biomechanical outcomes of hip-focused intervention programs

\begin{tabular}{|c|c|c|c|c|c|c|c|c|c|}
\hline & \multicolumn{5}{|c|}{ Program components } & \multicolumn{4}{|c|}{ Outcome measures } \\
\hline & NWB & WB-S & WB-F/T & $\mathrm{BAL}$ & TS & $\begin{array}{l}\text { Hip strength } \\
\text { ABD ER EXT }\end{array}$ & & & Biomechanics \\
\hline Baldon et $\mathrm{al}^{74}$ & $x$ & $x$ & $x$ & & $x$ & 个I5\%* Ecc & $0 \% \mathrm{Ecc}$ & NT & $\begin{array}{l}\text { - } \text { ipsilateral trunk inclination, pelvis } \\
\text { contralateral depression, hip } \\
\text { adduction and knee abduction during } \\
\text { a single leg squat }\end{array}$ \\
\hline Dolak et $\mathrm{al}^{78}$ & $x$ & $x$ & $x$ & & & 个21\%* Iso & $\uparrow 29 \%$ Iso & NT & - NT \\
\hline Earl and $\mathrm{Hoch}^{70}$ & $x$ & $x$ & & & $x$ & 个12\%* Iso & $\uparrow \mid 7 \% *$ Iso & NT & $\begin{array}{l}-\downarrow_{\text {peak internal knee abduction }} \\
\text { moment during stance phase of } \\
\text { running }\end{array}$ \\
\hline Ismail et $\mathrm{al}^{72}$ & $x$ & $x$ & & & & $\begin{array}{l}\uparrow 41 \% * \text { Con } \\
\uparrow 15 \% * \text { Ecc }\end{array}$ & $\begin{array}{l}\uparrow 33 \% * \text { Con } \\
\uparrow 29 \% * \text { Ecc }\end{array}$ & NT & - NT \\
\hline Khayambashi et al ${ }^{75}$ & $x$ & & & & & $\uparrow 32 \%-42 \% *$ Iso & $\uparrow 37 \%-56 \% *$ Iso & NT & $\bullet N T$ \\
\hline McCurdy et al $^{76}$ & & $x$ & & & & NT & NT & NT & $\begin{array}{l}\text { No change in knee abduction angle } \\
\text { during a bilateral drop-jump task }\end{array}$ \\
\hline Myer ${ }^{77}$ & & $x$ & $x$ & $x$ & $x$ & $\uparrow 15 \%-17 \% *$ Con & NT & NT & - NT \\
\hline Nakagawa et al ${ }^{79}$ & $x$ & $x$ & $x$ & & $x$ & 个I5\% Ecc & $\uparrow 6 \%$ Ecc & NT & $\bullet$ NT \\
\hline $\begin{array}{l}\text { Stearns and } \\
\text { Powers }^{71}\end{array}$ & & $x$ & & $x$ & $x$ & 个7\%* Iso & NT & 个8\%* Iso & 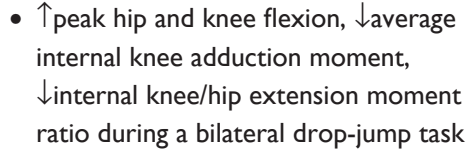 \\
\hline Willy and Davis ${ }^{80}$ & $x$ & $x$ & $x$ & & & $\uparrow 42 \% *$ Iso & $\uparrow 24.1 \% *$ Iso & NT & $\begin{array}{l}\text { - No significant kinematic changes } \\
\text { during running } \\
\text { - } \downarrow \text { hip adduction, hip internal rotation, } \\
\text { and contralateral pelvic drop during } \\
\text { single limb squat }\end{array}$ \\
\hline
\end{tabular}

Note: *Reported as statistically significant changes in strength.

Abbreviations: ABD, abduction; ER, external rotation; EXT, extension; Ecc, eccentric; Con, concentric; NWB, non-weight-bearing; WB-S, weight-bearing sagittal plane; WB-F/T, weight-bearing frontal/transverse plane; BAL, ballistic; TS, trunk stabilization; NT, not tested; Iso, isometric. 
the population targeted or stage in the rehabilitation process. Hip-focused interventions have been used in healthy athletes for knee injury prevention strategies, ${ }^{77}$ and in those diagnosed with PFP. ${ }^{70,72,74,75}$ The duration and volume of hip-focused programs have also varied considerably, with all programs occurring two to three times per week, but ranging from 4 to 12 weeks in duration. ${ }^{70-76}$

Because of the heterogeneity in populations and stages of rehabilitation, the exercises used to target the hip have also been variable. Some programs have focused strictly on isolated non-weight-bearing hip exercises, ${ }^{72,75}$ while others have used a combination of non-weight-bearing and weight-bearing/functional exercises focused either in one (sagittal) or multiple (frontal and transverse) planes. ${ }^{74,76,78,79}$ Although all programs were varied, common exercises were used between research groups. Side-lying hip abduction, prone hip extension, clam-shells (resisted), and seated hip external rotation were common non-weight-bearing exercises used in hip focused interventions. Weight-bearing exercises, including single limb squats and deadlifts, lunges, forward and lateral step-ups, and resisted hip external rotation are also prevalent amongst hip-focused programs. Additionally, some programs have included trunk strengthening as part of their hip-focused intervention, using standard exercises such as planks or incorporating an unstable support surface (eg, BOSU balance trainer) to encourage trunk activation and stabilization, ${ }^{71,74,77}$ while other programs have focused on the latter stages of rehabilitation by including plyometric activities in addition to standard strengthening techniques. ${ }^{71,77}$

Although the implementation methods of hip-focused intervention programs have been variable, these programs consistently produce improved measures of hip extension, abduction, and external rotation strength (Table 1). Strength gains of $7 \%-42 \%$ in hip abduction, ${ }^{22,70-72,75,77-80} 6 \%-56 \%$ in hip external rotation, ${ }^{70,72,75,78-80}$ and $8 \%$ in hip extension ${ }^{71}$ have been previously reported. However, these strength gains need to be interpreted cautiously. Although no previous studies have reported a significant reduction in hip strength, not all studies have reported statistically significant improvements in strength after hip-focused interventions ${ }^{74,80}$ which may be due to differences in the components, duration, and intensity of the programs, or the variability in the methodology of strength assessment, such as instrumentation (isokinetic versus handheld dynamometer), type of contraction (eccentric versus concentric versus isometric), and patient position (open versus closed chain). The largest gains in strength have typically been found in isometric strength, although we contend that eccentric strength may be of the most importance in controlling dynamic lower extremity valgus during jumping or cutting. Past research on the role of hip-focused interventions resulting in improved eccentric hip strength has been limited, ${ }^{72,74,79}$ and no studies have examined eccentric strength of the gluteus maximus or the combination of the three cardinal planes of hip motion.

More importantly, strength gains resulting from hipfocused interventions have translated to improved biomechanics at the hip and knee during athletic activities (Table 1). Previous studies report greater peak hip flexion during a jump landing ${ }^{71}$ and less hip adduction and internal rotation, ipsilateral trunk inclination, and contralateral pelvis depression during a single leg squat, ${ }^{74}$ despite only modest gains in hip strength. At the knee, hip-focused interventions may result in lower levels of knee adduction moments during running, ${ }^{70}$ and lower knee-hip extensor moment ratios and peak knee abduction angles and moments during jump landings, ${ }^{71}$ although other studies have found no specific biomechanical changes at the knee. ${ }^{76}$ Examining previous programs that have documented biomechanical outcomes after training, hip-focused interventions that include closed chain activities and trunk stabilization appear to make the largest positive impact on distal biomechanics. ${ }^{70,71,74}$ Considering the demands on the gluteus maximus during closed chain and ballistic exercises in the frontal and transverse planes and the limited research on the biomechanical effects of these exercises, further research to optimize the effects of hip-focused intervention is warranted.

\section{Practical application and conclusion}

Attention should be devoted to developing evidence to support progression of exercises with varying bases of support (Figure 5A), sports-related tasks with external load (Figure 5B), and resisted bands (Figure 5C and D). For instance, the resisted vertical bridge (Figure 5D) is a potential progression from the supine bilateral bridge with the ability to add changes in resistance in a vertical posture. The upright position transitions from the bridge to a closed kinetic chain posture as the femur loads into the acetabulum, which could be considered a more functional position in relation to human movement. The vertical bridge also allows the opportunity to engage the free upper extremities into other more "functional activities" that can promote perturbations to the trunk, ultimately engaging more core musculature than the isolated nature of the supine bridge.

There may be a tendency to assume a linear relationship between improved strength, improved biomechanical variables in a sports-related task like jumping or landing, 


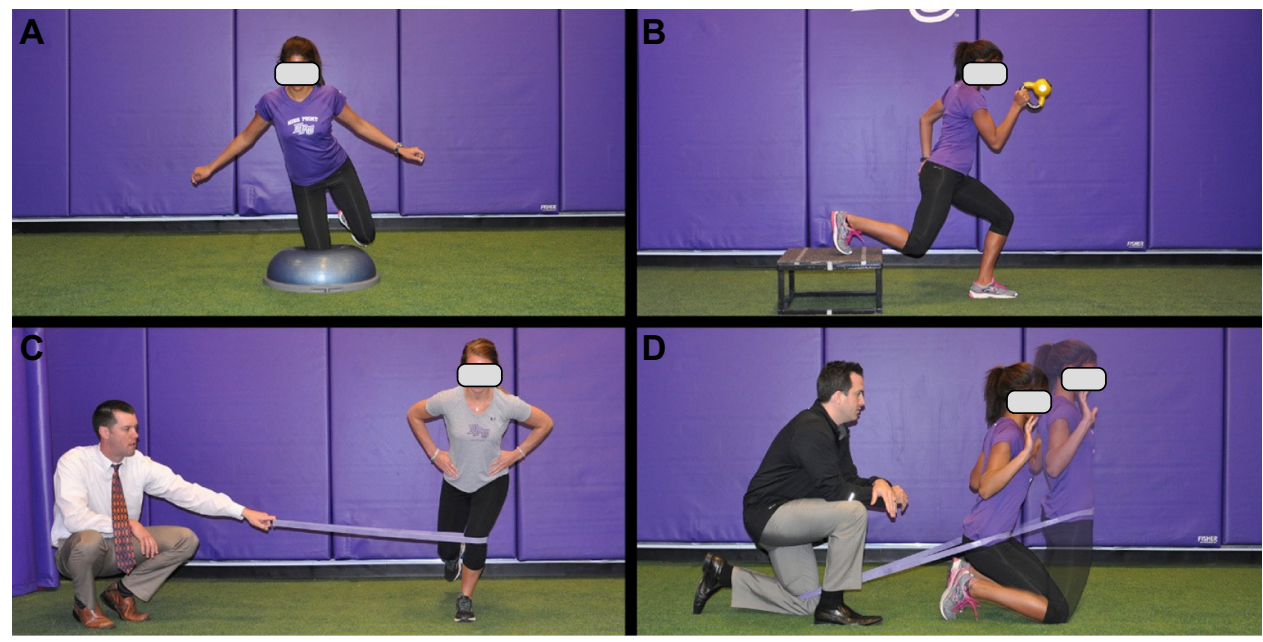

Figure 5 Late stage hip-focused exercises.

Notes: (A) BOSU single knee balance. (B) Weighted runner. (C) Resisted band single leg squats. (D) Resisted vertical bridge. Note that the resisted band in (C) should apply a slight force that progresses the athlete to activate the hip musculature to prevent lower extremity valgus. Care should be taken to progress the exercises and magnitude of resistance.

and improved biomechanical variables in the performance of the actual sport or activity. As this review has demonstrated, hip-focused exercises generally increase EMG activity, and increased EMG activity generally results in improved strength, which further results in improved task-related biomechanics. However, improved strength does not always result in changes to important biomechanical variables, ${ }^{81}$ and improved biomechanics in sports-related tasks does not necessarily equal improved biomechanical variables in performance of the sport itself. ${ }^{80}$ Controlling dynamic lower extremity valgus is complex (Figure 1) and likely involves a combination of strengthening and activation exercises and motor control of the hip, as well as use of feedback to facilitate integration into higher level activities. ${ }^{82-87}$ Even with the addition of feedback, hip-targeted strengthening alone is not the answer. Dynamic lower extremity valgus and hip muscle inhibition is likely influenced by pain or inflammation, ${ }^{88}$ body structure, ${ }^{89,90}$ fatigue, ${ }^{91-94}$ pubertal age and maturation, ${ }^{9,31,95}$ fear and other psychosocial variables, ${ }^{96-98}$ and prior injury. ${ }^{99,100}$ With the evidence and these variables in mind, a focus on strengthening the hip to control dynamic valgus is a great start for many reasons, including that it helps clinicians move away from a local focus to a more regional focus for pathologies at the knee. The next step in the evolution of treating patients with knee pathology is a global focus considering fixed factors like sex and body structure, re-education strategies like modes of feedback, physiological factors like pain, inflammation, and fatigue, and psychosocial factors like fear and anxiety (Figure 6). Figure 6 was constructed by the authors, based on the results of this evidenced-based review, to present a theoretical framework of the main steps to consider when initiating hip-focused neuromuscular exercises to modify dynamic lower extremity valgus, in addition to highlighting a few of the multivariate factors that should be considered when implementing hip-focused neuromuscular exercises in order to control dynamic lower extremity valgus. These factors likely play a critical role in the relative success of a program at each step along the continuum from initiating improved hip strength and activation to integrated neuromuscular control during a variety of movements to the final optimization of safe biomechanics during high-level activities and sports.

This clinical narrative is limited to the current strength of literature that was discussed. The strength and quality of literature is varied, with few randomized controlled trials. Therefore, caution should be used when interpreting results from lower quality and less controlled studies. Additionally, it was out of the scope of the current review to exhaustively cover and address special patient populations and adaptations that should be considered with some of the exercises presented. In summary, the research indicates that hip-focused neuromuscular exercise may be an important component to consider when treating patients with ACL and PFP knee pathologies. Importantly, it also appears that targeting hip musculature activation and strength may aid in modifying dynamic lower extremity valgus, which may help to reduce the risk of future ACL injury and PFP. Research should continue to develop to identify and understand the mechanistic relationship between optimized biomechanics 


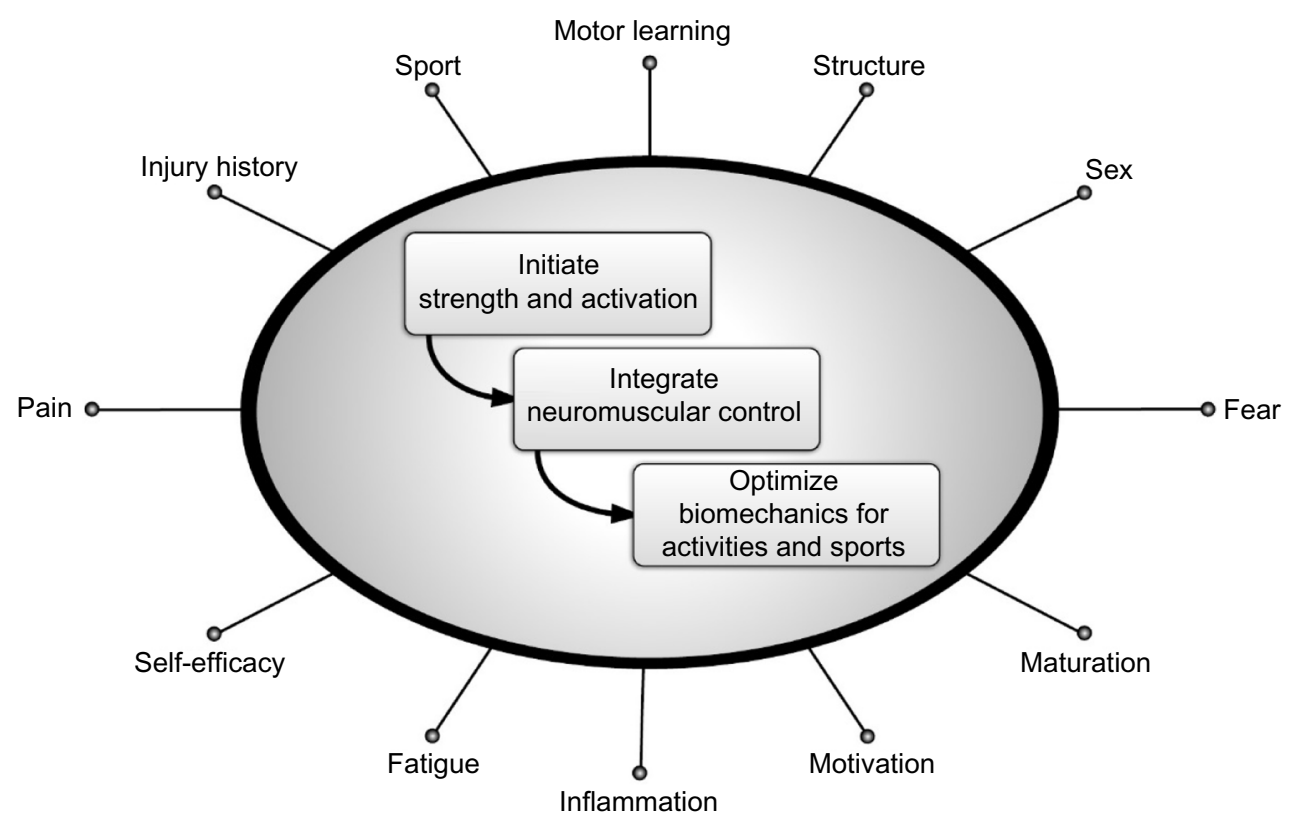

Figure 6 Theoretical framework for hip-focused neuromuscular exercises to modify dynamic lower extremity valgus.

Notes: Theoretical framework of the main steps to consider when initiating hip-focused neuromuscular exercises to modify dynamic lower extremity valgus. The spokes represent a non-exhaustive list of common factors that likely influence the relative success of a program.

during sports and hip-focused neuromuscular exercise interventions.

\section{Disclosure}

The authors report no conflicts of interest in this work.

\section{References}

1. Powers CM. The influence of abnormal hip mechanics on knee injury: a biomechanical perspective. J Orthop Sports Phys Ther. 2010;40(2): $42-51$.

2. Hewett TE, Myer GD, Ford KR, et al. Biomechanical measures of neuromuscular control and valgus loading of the knee predict anterior cruciate ligament injury risk in female athletes: a prospective study. $\mathrm{Am}$ J Sports Med. 2005;33(4):492-501.

3. Hewett TE, Myer GD, Ford KR. Anterior cruciate ligament injuries in female athletes: Part 1, mechanisms and risk factors. Am J Sports Med. 2006;34(2):299-311.

4. Paterno MV, Schmitt LC, Ford KR, et al. Biomechanical measures during landing and postural stability predict second anterior cruciate ligament injury after anterior cruciate ligament reconstruction and return to sport. Am J Sports Med. 2010;38(10):1968-1978.

5. Myer GD, Ford KR, Di Stasi SL, Barber Foss KD, Micheli LJ, Hewett TE. High knee abduction moments are common risk factors for patellofemoral pain (PFP) and anterior cruciate ligament (ACL) injury in girls: is PFP itself a predictor for subsequent ACL injury? $\mathrm{Br} J$ Sports Med. 2015;49(2):118-122.

6. Ford KR, Myer GD, Hewett TE. Valgus knee motion during landing in high school female and male basketball players. Med Sci Sports Exerc. 2003;35(10):1745-1750.

7. Ford KR, Myer GD, Toms HE, Hewett TE. Gender differences in the kinematics of unanticipated cutting in young athletes. Med Sci Sports Exerc. 2005;37(1):124-129.

8. Ford KR, Myer GD, Smith RL, Vianello RM, Seiwert SL, Hewett TE. A comparison of dynamic coronal plane excursion between matched male and female athletes when performing single leg landings. Clin Biomech. 2006;21(1):33-40.
9. Ford KR, Shapiro R, Myer GD, van den Bogert AJ, Hewett TE. Longitudinal sex differences during landing in knee abduction in young athletes. Med Sci Sports Exerc. 2010;42(10):1923-1931.

10. Malinzak RA, Colby SM, Kirkendall DT, Yu B, Garrett WE. A comparison of knee joint motion patterns between men and women in selected athletic tasks. Clin Biomech. 2001;16(5):438-445.

11. Hewett TE, Myer GD, Ford KR. Decrease in neuromuscular control about the knee with maturation in female athletes. J Bone Joint Surg Am. 2004;86-A(8):1601-1608.

12. Chappell JD, Yu B, Kirkendall DT, Garrett WE. A comparison of knee kinetics between male and female recreational athletes in stop-jump tasks. Am J Sports Med. 2002;30(2):261-267.

13. McLean SG, Huang X, Su A, van den Bogert AJ. Sagittal plane biomechanics cannot injure the ACL during sidestep cutting. Clin Biomech. 2004; 19:828-838.

14. Kernozek TW, Torry MR, Van Hoof H, Cowley H, Tanner S. Gender differences in frontal and sagittal plane biomechanics during drop landings. Med Sci Sports Exerc. 2005;37(6):1003-1012.

15. Zeller BL, McCrory JL, Kibler WB, Uhl TL. Differences in kinematics and electromyographic activity between men and women during the single-legged squat. Am J Sports Med. 2003;31(3):449-456.

16. Pappas E, Hagins M, Sheikhzadeh A, Nordin M, Rose D. Biomechanical differences between unilateral and bilateral landings from a jump: gender differences. Clin J Sport Med. 2007;17(4):263-268.

17. Hewett TE, Ford KR, Myer GD, Wanstrath K, Scheper M. Gender differences in hip adduction motion and torque during a single leg agility maneuver. J Orthop Res. 2006;24(3):416-421.

18. Hewett TE, Stroupe AL, Nance TA, Noyes FR. Plyometric training in female athletes. Decreased impact forces and increased hamstring torques. Am J Sports Med. 1996;24(6):765-773.

19. Carson DW, Ford KR. Sex differences in knee abduction during landing: a systematic review. Sports Health. 2011;3(4):373-382.

20. Olsen OE, Myklebust G, Engebretsen L, Bahr R. Injury mechanisms for anterior cruciate ligament injuries in team handball: a systematic video analysis. Am J Sports Med. 2004;32(4):1002-1012.

21. Krosshaug T, Nakamae A, Boden BP, et al. Mechanisms of anterior cruciate ligament injury in basketball: video analysis of 39 cases. Am J Sports Med. 2007;35(3):359-367. 
22. Boden BP, Dean GS, Feagin JA, Garrett WE. Mechanisms of anterior cruciate ligament injury. Orthopedics. 2000;23(6):573-578.

23. Brent J, Myer GD, Ford KR, Paterno M, Hewett T. The effect of sex and age on isokinetic hip abduction torques. J Sport Rehabil. 2013; 22(1):41-46.

24. Ford KR, Taylor-Haas JA, Genthe K, Hugentobler J. Relationship between hip strength and trunk motion in college cross-country runners. Med Sci Sports Exerc. 2013;45(6):1125-1130.

25. Taylor-Haas JA, Hugentobler JA, DiCesare CA, et al. Reduced hip strength is associated with increased hip motion during running in young adult and adolescent male long-distance runners. Int $J$ Sports Phys Ther. 2014;9(4):456-467.

26. Prins MR, van der Wurff P. Females with patellofemoral pain syndrome have weak hip muscles: a systematic review. Aust J Physiother. 2009;55(1):9-15.

27. Souza RB, Powers CM. Differences in hip kinematics, muscle strength, and muscle activation between subjects with and without patellofemoral pain. J Orthop Sports Phys Ther. 2009;39(1):12-19.

28. Willson JD, Davis IS. Lower extremity mechanics of females with and without patellofemoral pain across activities with progressively greater task demands. Clin Biomech. 2008;23(2):203-211.

29. Ireland ML. The female ACL: why is it more prone to injury? Orthop Clin North Am. 2002;33(4):637-651.

30. Knapik JJ, Bauman CL, Jones BH, Harris JM, Vaughan L. Preseason strength and flexibility imbalances associated with athletic injuries in female collegiate athletes. Am J Sports Med. 1991;19(1):76-81.

31. Ford KR, Myer GD, Hewett TE. Longitudinal effects of maturation on lower extremity joint stiffness in adolescent athletes. Am J Sports Med. 2010;38(9):1829-1837.

32. Decker MJ, Torry MR, Wyland DJ, Sterett WI, Richard Steadman J. Gender differences in lower extremity kinematics, kinetics and energy absorption during landing. Clin Biomech. 2003;18(7):662-669.

33. DeVita P, Hortobagyi T, Barrier J. Gait biomechanics are not normal after anterior cruciate ligament reconstruction and accelerated rehabilitation. Med Sci Sports Exerc. 1998;30(10):1481-1488.

34. Souza RB, Arya S, Pollard CD, Salem G, Kulig K. Patellar tendinopathy alters the distribution of lower extremity net joint moments during hopping. J Appl Biomech. 2010;26(3):249-255.

35. Lephart SM, Abt JP, Ferris CM, et al. Neuromuscular and biomechanical characteristic changes in high school athletes: a plyometric versus basic resistance program. Br J Sports Med. 2005;39(12): 932-938.

36. Shultz SJ, Beynnon BD, Schmitz RJ. Sex differences in coupled knee motions during the transition from non-weight-bearing to weightbearing. J Orthop Res. 2009;27(6):717-723.

37. Moore KL. Clinically Oriented Anatomy. Baltimore, MD, USA: Williams and Wilkins; 1992.

38. Kumagai M, Naoto S, Higuchi F. Functional evaluation of hip abductor muscles with use of magnetic resonance imaging. J Orthop Res. 1997;15: 888-893.

39. Inman VT. Functional aspects of the abuctor muscles of the hip. $J$ Bone Joint Surg Am. 1947;29(3):607-619.

40. Pfirrmann CW, Chung CB, Theumann NH, Trudell DJ, Resnick D. Greater trochanter of the hip: attachment of the abductor mechanism and a complex of three bursae-MR imaging and MR bursography in cadavers and MR imaging in asymptomatic volunteers. Radiology. 2001;221(2): 469-477.

41. Gottschalk F, Kourosh S, Leveau B. The functional anatomy of tensor fasciae latae and gluteus medius and minimus. J Anat. 1989;166 179-189.

42. Soderberg GL, Dostal WF. Electromyographic study of three parts of the gluteus medius muscle during functional activities. Phys Ther. 1978;58(6):691-696.

43. Lyons K, Perry J, Gronley JK, Barnes L, Antonelli D. Timing and relative intensity of hip extensor and abductor muscle action during level and stair ambulation. An EMG study. Phys Ther. 1983;63(10): 1597-1605.
44. Kendall FP, McCreary EK, Provance PG. Muscles Testing and Function. 4th ed. Philadelphia, PA, USA: Lippincott Williams \& Wilkins; 1993.

45. Earl JE. Gluteus medius activity during 3 variations of isometric singleleg stance. J Sport Rehabil. 2004;13:1-11.

46. Schmitz RJ, Riemann BL, Thompson T. Gluteus medius activity during isometric closed-chain hip rotation. $J$ Sport Rehabil. 2002;11: 179-188.

47. Neumann DA. Biomechanical analysis of selected principles of hip joint protection. Arthritis Care Res. 1989;2(4):146-155.

48. Neumann DA, Cook TM, Sholty RL, Sobush DC. An electromyograpic analysis of hip abductor muscle activity when subjects are carrying loads in one of both hands. Phys Ther. 1992;72(3):207-217.

49. Anderson FC, Pandy MG. Individual muscle contributions to support in normal walking. Gait Posture. 2003;17(2):159-169.

50. Andersen LL, Magnusson SP, Nielsen M, Haleem J, Poulsen K, Aagaard P. Neuromuscular activation in conventional therapeutic exercises and heavy resistance exercises: implications for rehabilitation. Phys Ther. 2006;86(5):683-697.

51. DiStefano LJ, Blackburn JT, Marshall SW, Padua DA. Gluteal muscle activation during common therapeutic exercises. J Orthop Sports Phys Ther. 2009;39(7):532-540.

52. Bolgla LA, Uhl TL. Electromyographic analysis of hip rehabilitation exercises in a group of healthy subjects. J Orthop Sports Phys Ther 2005;35(8):487-494.

53. Boren K, Conrey C, Le Coguic J, Paprocki L, Voight M, Robinson TK. Electromyographic analysis of gluteus medius and gluteus maximus during rehabilitation exercises. Int J Sports Phys Ther. 2011;6(3): 206-223.

54. Selkowitz DM, Beneck GJ, Powers CM. Which exercises target the gluteal muscles while minimizing activation of the tensor fascia lata? Electromyographic assessment using fine-wire electrodes. J Orthop Sports Phys Ther. 2013;43(2):54-64.

55. Ekstrom RA, Donatelli RA, Carp KC. Electromyographic analysis of core trunk, hip, and thigh muscles during 9 rehabilitation exercises. J Orthop Sports Phys Ther. 2007;37(12):754-762.

56. Ayotte NW, Stetts DM, Keenan G, Greenway EH. Electromyographical analysis of selected lower extremity muscles during 5 unilateral weightbearing exercises. J Orthop Sports Phys Ther. 2007;37(2):48-55.

57. Lubahn AJ, Kernozek TW, Tyson TL, Merkitch KW, Reutemann P, Chestnut JM. Hip muscle activation and knee frontal plane motion during weight-bearing therapeutic exercises. Int J Sports Phys Ther. 2011;6(2):92-103

58. Chmielewski TL, Myer GD, Kauffman D, Tillman SM. Plyometric exercise in the rehabilitation of athletes: physiological responses and clinical application. J Orthop Sports Phys Ther. 2006;36(5):308-319.

59. Myer GD, Ford KR, Hewett TE. Rationale and clinical techniques for anterior cruciate ligament injury prevention among female athletes. J Athl Train. 2004;39(4):352-364.

60. Myer GD, Paterno MV, Ford KR, Hewett TE. Neuromuscular training techniques to target deficits before return to sport after anterior cruciate ligament reconstruction. J Strength Cond Res. 2008; 22(3):987-1014

61. Myer GD, Ford KR, Brent JL, Hewett TE. An integrated approach to change the outcome Part II: Targeted neuromuscular training techniques to reduce identified ACL injury risk factors. J Strength Cond Res. 2012; 26(8):2272-2292.

62. Struminger AH, Lewek MD, Goto S, Hibberd E, Blackburn JT. Comparison of gluteal and hamstring activation during five commonly used plyometric exercises. Clin Biomech. 2013;28(7):783-789.

63. Hanson AM, Padua DA, Troy Blackburn J, Prentice WE, Hirth CJ. Muscle activation during side-step cutting maneuvers in male and female soccer athletes. J Athl Train. 2008;43(2):133-143.

64. Lee JH, Cynn HS, Kwon OY, et al. Different hip rotations influence hip abductor muscles activity during isometric side-lying hip abduction in subjects with gluteus medius weakness. $J$ Electromyogr Kinesiol. 2014;24(2):318-324. 
65. Worrell TW, Karst G, Adamczyk D, et al. Influence of joint position on electromyographic and torque generation during maximal voluntary isometric contractions of the hamstrings and gluteus maximus muscles. J Orthop Sports Phys Ther. 2001;31(12):730-740.

66. Powers CM. The influence of altered lower-extremity kinematics on patellofemoral joint dysfunction: a theoretical perspective. J Orthop Sports Phys Ther. 2003;33(11):639-646.

67. Kopper B, Ureczky D, Tihanyi J. Trunk position influences joint activation pattern and physical performance during vertical jumping. Acta Physiol Hung. 2012;99(2):194-205.

68. Teng HL, Powers CM. Influence of trunk posture on lower extremity energetics during running. Med Sci Sports Exerc. 2015;47(3):625-630.

69. Farrokhi S, Pollard CD, Souza RB, Chen YJ, Reischl S, Powers CM. Trunk position influences the kinematics, kinetics, and muscle activity of the lead lower extremity during the forward lunge exercise. JOrthop Sports Phys Ther. 2008;38(7):403-409.

70. Earl JE, Hoch AZ. A proximal strengthening program improves pain, function, and biomechanics in women with patellofemoral pain syndrome. Am J Sports Med. 2011;39(1):154-163.

71. Stearns KM, Powers CM. Improvements in hip muscle performance result in increased use of the hip extensors and abductors during a landing task. Am J Sports Med. 2014;42(3):602-609.

72. Ismail MM, Gamaleldein MH, Hassa KA. Closed kinetic chain exercises with or without additional hip strengthening exercises in management of patellofemoral pain syndrome: a randomized controlled trial. Eur $J$ Phys Rehabil Med. 2013;49(5):687-698.

73. Garrison JC, Bothwell J, Cohen K, Conway J. Effects of hip strengthening on early outcomes following anterior cruciate ligament reconstruction. Int J Sports Phys Ther. 2014;9(2):157-167.

74. Baldon Rde M, Serrao FV, Scattone Silva R, Piva SR. Effects of functional stabilization training on pain, function, and lower extremity biomechanics in women with patellofemoral pain: a randomized clinical trial. J Orthop Sports Phys Ther. 2014;44(4):A240-A248.

75. Khayambashi K, Mohammadkhani Z, Ghaznavi K, Lyle MA, Powers CM. The effects of isolated hip abductor and external rotator muscle strengthening on pain, health status, and hip strength in females with patellofemoral pain: a randomized controlled trial. J Orthop Sports Phys Ther. 2012;42(1):22-29.

76. McCurdy K, Walker J, Saxe J, Woods J. The effect of short-term resistance training on hip and knee kinematics during vertical drop jumps. J Strength Cond Res. 2012;26(5):1257-1264.

77. Myer GD, Brent JL, Ford KR, Hewett TE. A pilot study to determine the effect of trunk and hip-focused neuromuscular training on hip and knee isokinetic strength. Br J Sports Med. 2008;42(7):614-619.

78. Dolak KL, Silkman C, Medina McKeon J, Hosey RG, Lattermann C, Uhl TL. Hip strengthening prior to functional exercises reduces pain sooner than quadriceps strengthening in females with patellofemoral pain syndrome: a randomized clinical trial. J Orthop Sports Phys Ther. 2011;41(8):560-570.

79. Nakagawa TH, Muniz TB, Baldon Rde M, Dias Maciel C, de Menezes Reiff RB, Serrao FV. The effect of additional strengthening of hip abductor and lateral rotator muscles in patellofemoral pain syndrome: a randomized controlled pilot study. Clin Rehabil. 2008; 22(12):1051-1060.

80. Willy RW, Davis IS. The effect of a hip strengthening program on mechanics during running and during a single leg squat. J Orthop Sports Phys Ther. 2011;41(9):625-632.

81. Herman DC, Weinhold PS, Guskiewicz KM, Garrett WE, Yu B, Padua DA. The effects of strength training on the lower extremity biomechanics of female recreational athletes during a stop-jump task. Am J Sports Med. 2008;36(4):733-740.

82. Willy RW, Scholz JP, Davis IS. Mirror gait retraining for the treatment of patellofemoral pain in female runners. Clin Biomech. 2012;27(10): 1045-1051.
83. Noehren B, Scholz J, Davis I. The effect of real-time gait retraining on hip kinematics, pain and function in subjects with patellofemoral pain syndrome. Br J Sports Med. 2011;45(9):691-696.

84. Benjaminse A, Gokeler A, Dowling AV, et al. Optimization of the anterior cruciate ligament injury prevention paradigm: novel feedback techniques to enhance motor learning and reduce injury risk. J Orthop Sports Phys Ther. 2015;45(3):170-182.

85. Ford KR, DiCesare CA, Myer GD, Hewett TE. Real-time biofeedback to target risk of anterior cruciate ligament injury: a technical report for injury prevention and rehabilitation. J Sport Rehabil. 2015; Technical Notes. pii: 2013-0138.

86. Gokeler A, Benjaminse A, Hewett TE, et al. Feedback techniques to target functional deficits following anterior cruciate ligament reconstruction: implications for motor control and reduction of second injury risk. Sports Med. 2013;43(11):1065-1074.

87. Wouters I,AlmonroederT, Dejarlais B, LaackA, Willson JD, KernozekTW. Effects of a movement training program on hip and knee joint frontal plane running mechanics. Int J Sports Phys Ther. 2012; 7(6):637-646.

88. Freeman S, Mascia A, McGill S. Arthrogenic neuromusculature inhibition: a foundational investigation of existence in the hip joint. Clin Biomech. 2013;28(2):171-177.

89. Nguyen AD, Shultz SJ, Schmitz RJ. Landing biomechanics in participants with different static lower extremity alignment profiles. $J$ Athl Train. 2015;50(5):498-507.

90. Nguyen AD, Shultz SJ, Schmitz RJ, Luecht RM, Perrin DH. A preliminary multifactorial approach describing the relationships among lower extremity alignment, hip muscle activation, and lower extremity joint excursion. J Athl Train. 2011;46(3):246-256.

91. Verrelst R, De Clercq D, Willems TM, Victor J, Witvrouw E. Contribution of a muscle fatigue protocol to a dynamic stability screening test for exertional medial tibial pain. Am J Sports Med. 2014;42(5): $1219-1225$.

92. Willson JD, Petrowitz I, Butler RJ, Kernozek TW. Male and female gluteal muscle activity and lower extremity kinematics during running. Clin Biomech. 2012;27(10):1052-1057.

93. Patrek MF, Kernozek TW, Willson JD, Wright GA, Doberstein ST. Hip-abductor fatigue and single-leg landing mechanics in women athletes. J Athl Train. 2011;46(1):31-42.

94. Kernozek TW, Torry MR, Iwasaki M. Gender differences in lower extremity landing mechanics caused by neuromuscular fatigue. $\mathrm{Am} \mathrm{J}$ Sports Med. 2008;36(3):554-565.

95. Quatman-Yates CC, Myer GD, Ford KR, Hewett TE. A longitudinal evaluation of maturational effects on lower extremity strength in female adolescent athletes. Pediatr Phys Ther. 2013;25(3):271-276.

96. Gardinier ES, Manal K, Buchanan TS, Snyder-Mackler L. Gait and neuromuscular asymmetries after acute anterior cruciate ligament rupture. Med Sci Sports Exerc. 2012;44(8):1490-1496.

97. Ardern CL, Taylor NF, Feller JA, Whitehead TS, Webster KE. Psychological responses matter in returning to preinjury level of sport after anterior cruciate ligament reconstruction surgery. Am J Sports Med. 2013;41(7):1549-1558.

98. Lentz TA, Zeppieri G Jr, George SZ, et al. Comparison of physical impairment, functional, and psychosocial measures based on fear of reinjury/lack of confidence and return-to-sport status after ACL reconstruction. Am J Sports Med. 2015;43(2):345-353.

99. Paterno MV, Rauh MJ, Schmitt LC, Ford KR, Hewett TE. Incidence of second ACL injuries 2 years after primary ACL reconstruction and return to sport. Am J Sports Med. 2014;42(7):1567-1573.

100. Paterno MV, Rauh MJ, Schmitt LC, Ford KR, Hewett TE. Incidence of contralateral and ipsilateral anterior cruciate ligament (ACL) injury after primary ACL reconstruction and return to sport. Clin J Sport Med. 2012;22(2):116-121. 
Open Access Journal of Sports Medicine

Dovepress

\section{Publish your work in this journal}

Open Access Journal of Sports Medicine is an international, Visit http://www.dovepress.com/testimonials.php to read real quotes peer-reviewed, open access journal publishing original research, from published authors.

reports, reviews and commentaries on all areas of sports

medicine. The manuscript management system is completely

online and includes a very quick and fair peer-review system.

Submit your manuscript here: http://www.dovepress.com/open-access-journal-of-sports-medicine-journal 